\title{
Construction and Practice of the Teaching Mode of "Course+Research Club" in Colleges and Universities-Taking Taekwondo as an Example
}

\author{
Hu Hongquan \\ Kaifeng University, Henan, Kaifeng, 475004
}

Keywords: research club; course; Taekwondo; teaching mode

\begin{abstract}
The research club is an important part of college student clubs, is also an important way for creating the atmosphere of ideological and political education, contributes to strengthening college students' academic research ability, and helps to cultivate independent practice and innovation ability. This paper builds the teaching mode of "course+research club" through research and practice of "taekwondo teaching courses" based on the combination of theoretical taekwondo courses with research clubs from the perspectives of the teaching method, teaching principle, teaching objective and teaching evaluation system, so as to promote college students' understanding of the theoretical knowledge of taekwondo and practical research ability, cultivate their independent learning and thinking ability, and constantly break through themselves in constant learning and practice.
\end{abstract}

\section{Introduction}

As our country attaches great importance to traditional culture, Chinese colleges and universities also extensively add martial art courses such as taekwondo in the form of sport courses to inherit the traditional Chinese culture. However, for the current teaching state, taekwondo and other martial art courses are set in grade one or grade two of universities using the teaching mode that teachers teach actions, while students copy and practice the actions, using an appraisal system assessing students' taekwondo actions. This teaching mode has seriously hindered students' enthusiasm for learning, and development of their practice and innovation ability. The teaching mode of "course+research club" is formed according to the constructivism learning theory, and is of great significance for the independent learning and thinking ability and research and thinking ability of college students. Therefore, building an effective teaching mode is a phenomenon to be extensively improved in colleges and universities of China at present. It is necessary to firstly have theoretical knowledge teaching, secondly to innovate the teaching process, establish the innovative teaching concept, and build a student-oriented independent teaching mode combining theoretical taekwondo courses with practice research, so as to research and improve the teaching mode of sport courses such as martial arts in colleges and universities.

\section{Theoretical Overview of the Teaching Mode of "Course+ Research Club" in Colleges and Universities}

The teaching mode of "course+research club" in colleges and universities is a new talent cultivation mode, and is a practical teaching mode based on college student clubs. The teaching mode of "course+research club" changes the previous simple teaching mode that "teachers teach, while students listen", tries to "learn knowledge in class, practice skills after class, find new problems in practice, and return to class to solve the problems", and converts passive learning into active participation in practice. The "course+research club" in colleges and universities can be defined as a student mass organization that is freely formed by students on a voluntary basis and independently carries out activities according to the teaching objective. This teaching mode can break the limitations of grades, departments and schools, unite students with similar hobbies and interests, exert their strong points in some aspects, and carry out activities that are beneficial to students' physical and mental health. Nowadays, colleges and universities have various club forms, 
such as drama club, math association, drawing society and so on. In this paper, taking taekwondo course as an example, the teaching objective is to cultivate college students' interests in learning taekwondo and carry forward the traditional Chinese culture; set up an innovative teaching evaluation system that does not assess a student based on his scores, and achieve the purpose of cultivating underachievers' self-confidence in learning, managing student's individual differences, and promoting well-rounded development of all students.

\section{Construction and Practice of "Course+Research Club" in Colleges and Universities}

The "course+research club" is built and practiced to set up college students' concepts of and responsibilities for spreading excellent traditional cultures such as taekwondo, and improve college students' independent learning ability to some extent. Therefore, it is in urgent of improving the teaching mode of sport courses such as taekwondo.

According to the theoretical knowledge module and teaching plan of taekwondo, various corresponding taekwondo clubs are established, and corresponding courses are offered to the clubs. Moreover, gradient teaching is implemented according to students' foundations. When students get to learn taekwondo, they have different foundations and abilities. According to the teaching method of "treating all students similarly", the teaching effect must be very poor. Therefore, teachers are requested to acquire students' foundation and ability information by way of testing, asking questions or the like before giving new lessons, and teach students after dividing them into high, intermediate and low gradients according to the levels of their foundation and ability. The highest gradient forms a representative club team, and only needs teachers' guidance in the aspect of very difficult actions; intermediate gradient is taught at a medium speed according to the normal teaching plan and syllabus; and the lowest gradient should be slowly taught step by step. The gradient of a student is not fixed, and is changed according to the actual situation of passing the test in a stage.

The teaching content of taekwondo is an important carrier for college students to learn taekwondo. The teaching content of taekwondo in the teaching mode of "course+ research club" includes the teaching principle, teaching objective, teaching process and the like.

The teaching principle in the teaching mode of "course+ research club" in colleges and universities is to give priority to cultivate students' comprehensive ability, develop their individualities and commonness together, integrate taekwondo in university courses, associate research clubs of college students, improve college students' learning methods and habits, and pay attention to cultivating their independent thinking ability.

According to the teaching principle, the teaching objective is to learn basic theoretical contents by popularizing martial arts and culture in taekwondo courses, basically know about and understand relevant knowledge of taekwondo, stimulate learning interests, deeply research theoretical taekwondo knowledge with the help of the practical platform of research clubs, enable students to skillfully master martial art actions based on combination of cultural knowledge with martial art knowledge, and help college students to cultivate independent research ability and consciousness of spreading taekwondo.

The teaching process is guided by the teaching principle, relies on the teaching objective, and improves students' understanding and research of taekwondo. The teaching process of taekwondo should not only pay attention to the correlation between taekwondo and college students' learning life, namely the spread range of taekwondo courses, but also pay attention to the richness of taekwondo activities in research clubs, promote college students' independent thinking by participating in a variety of taekwondo competitions, watching excellent taekwondo competition programs and other activities, continuously improve their taekwondo learning methods, and adjust their actions, namely the spread depth of taekwondo courses. The teaching process combining courses and research clubs plays an important role in promoting college students to learn taekwondo.

The teaching evaluation system in the teaching mode of "course+research club" in colleges and universities should abandon the traditional appraisal system that "score determines everything". The score is undoubtedly important, but it is necessary to investigate students' learning situation in many 
ways and in multi-levels under the guidance of focus on developing students' individualities and commonness together through abundant taekwondo teaching activities and scientific teaching methods, improve the teaching evaluation system, and then realize the teaching objective of taekwondo courses to the maximum extent. For sport courses similar to taekwondo, students show greatly different learning processes and results. A scientific appraisal system is used to highlight students' uniqueness, find their strengths, motivate them to raise doubts, and constantly overcome themselves in every exam.

The teaching mode of "course+research club" is built in colleges and universities to break the limitation of theoretical teaching and practical teaching, and has a positive influence on the formation of college students' independent learning habits. Through this teaching mode, theoretical learning of taekwondo is combined with practical operation, so that college students strengthen their independent learning consciousness, can actively think, and positively research practical actions of taekwondo from the perspective of theoretical knowledge. Moreover, in this process, students can cultivate their unity and cooperation ability, learn relevant taekwondo contents from others through communication with others, and form self-adjustment and other reflection consciousness through self-comparison, thus slowly forming habits of positive and independent learning.

The teaching mode of "course+research club" in colleges and universities fully reflects the teaching concept of equality and co-learning between teachers and students. Therefore, PE teachers in colleges and universities should improve the teaching concept, actively develop independent learning activities of students in the teaching process, pay attention to communication between teachers and students, combine teaching with researches, study students' problems together with students, not only establish the concept of lifelong learning, but also reflect through the teaching process, communicate with excellent teachers, and build platforms of free dialogue and common development between teachers and students, so as to promote the teaching mode of "course+research club" in colleges and universities.

\section{Conclusion}

College student club is an important part of campus culture. With the development of the times, it is necessary to fully know about the development laws of college student clubs, and dare to innovate and practice. Reforming the teaching mode in colleges and universities with the help of the advantages of research clubs intended to cultivate college students' innovative thinking and practical ability has been an inevitable trend. The teaching mode of "course+research club" in colleges and universities actively carries out research-oriented teaching by combining theoretical taekwondo courses with research clubs, improves the teaching mode in colleges and universities in the aspects of the teaching principle, teaching objective, teaching method, teaching evaluation and so on, effectively realizes deep fusion of the theoretical teaching with the practical operation, develop college students' individualities and commonness, improves students' comprehensive ability of sport courses similar to taekwondo, and provides theoretical proposals on cultivation of internationalized talents in colleges and universities and construction and practice of the teaching mode of "course+research club" in colleges and universities of China. The next work is to popularize in colleges and universities of China.

\section{References}

[1] Ma Liguo. Integration and Application of Taekwondo Curriculum Resources in Colleges and Universities of Harbin [D]. Northeast Normal University, 2012.

[2] Luo Zhenzi, Liu Chang and Zhang Tao. Management of Research Clubs in Colleges and Universities from the Perspective of Self-Organization Theory-Taking Research Clubs of Guangxi Normal University as an Example [J]. Knowledge Economy, 2009 (1): 156-157.

[3] Zhang Yanyong, Shi Fuchun and Zhou Yuehong. Research on Construction of PE Classroom Teaching Mode of "General Course+Compulsory Course+Club" in Higher Vocational Colleges [J]. Journal of Shanxi Coal-Mining Administrators College, 2012, 25 (1): 215-217. 